\title{
Aprovechamientos de Andrés Bello: una estrategia americana
}

\author{
Joaquín Trujillo \\ Centro de Estudios Públicos, Chile
}

\begin{abstract}
ResUmen: En la primera mitad del siglo XIX y en un contexto de poderosas tendencias separatistas, América hispana tiene que definir su relación con esa parte del mundo que entonces se llamaba 'civilizado'. La obra de Andrés Bello puede ser entendida como un inmenso conjunto de propuestas para enfrentar ese proceso. El autor observa que la voz 'aprovechamiento' (de uso progresivo desde fines del siglo XV y no poco generalizado en los siglos XVIII y XIX) habría sido resignificada en tanto concepto por el caraqueño como una manera de abreviar las políticas de concordancia pensadas desde el punto de vista de los americanos. Además, el artículo propone que el conjunto del corpus de Bello puede interpretarse sistemáticamente en torno a ese concepto, mientras que sus notas de lectura en la Biblioteca del Museo Británico sirven para trazar los flujos de dicho aprovechamiento.
\end{abstract}

Palabras clave: Andrés Bello, Hispanoamérica, siglo XIX, aprovechamiento, concordancia, estrategia americana

RECIBIDO: noviembre 2020/ ACEPTADO: abril 2021

\section{Andrés Bello's Advantages: An American Strategy}

AвSTRACT: In the first half of the 19th Century, and in the context of powerful separatist tendencies, Hispanic America had to define its relation-

JoAquín TRUJlLLo es abogado, candidato a Doctor en Literatura y Máster en Estudios Latinoamericanos por la Universidad de Chile. Investigador del Centro de Estudios Públicos (CEP), Chile. Autor de Andrés Bello: libertad, imperio, estilo (Roneo, 2019), Lobelia (Ril, 2017), entre otros. Dirección: Monseñor Sótero Sanz 162, Providencia, Santiago, Chile, CP 7500011. Email: jtrujillo@cepchile.cl.

Este artículo se enmarca en la escritura de una tesis doctoral en literatura, la cual, entre otras cosas, se concentra en los 'aprovechamientos' de Andrés Bello. El autor agradece las sugerencias de Ignacio Álvarez y las dos excelentes observaciones del arbitraje ciego. 
ship with that part of the world that was called 'civilized' at that time. Andrés Bello's work can be understood as an immense set of proposals to face this process. The author observes that the word 'astuteness' (of increasing use since the end of the 15th Century and generalized in the 18th and 19th Centuries) would have been re-signified as a concept by the Caracas citizen as a way of abbreviating the concordance policies thought from the point of view of the Americans. Furthermore, the article proposes that the whole of Bello's corpus can be systematically interpreted around this concept, while his reading notes in the British Museum Library serve to trace the flows of said use.

KeYwords: Andrés Bello, Hispanic America, 19 ${ }^{\text {th }}$ Century, astuteness, advantages, concordance, American strategy

ReCeIved: November 2020 / AcCEPTED: April 2021

os procesos de descolonización durante los siglos XVIII a XX significaron filosofías y estrategias que van desde las de los Founding Fathers en Estados Unidos, a las de Aimé Cesaire, en la Martinica francesa, pasando por otros intelectuales de acción como José Martí, en Cuba, o Andrés Bello en la Sudamérica de mediados del siglo XIX.

Con la caída del Imperio español, que significó la actualización de las concordancias americanas respecto del mundo al que se llamaba 'civilizado' (Ferguson 2012; Dussel 2007), a la América hispana se la creyó apta para ponerse al día a través de un proceso en el que la pregunta por cómo adquirir saberes foráneos, compaginándolos, eso sí, con la preservación de las independencias, se volvería insoslayable.

En Trujillo (2019) propuse que eran los tres ejes que le dan título al libro (libertad, imperio, estilo) los que resumían buena parte de la vida y obra intelectual y política de Andrés Bello. Además, que era la 'gramatocracia' — un neologismo de esos que a Bello no gustaban- la palabra que resumía su filosofía práctica o, mejor dicho, su estilo. En esa misma investigación nada más esbocé la idea de que Bello había promovido concordancias con ese mundo que él, al igual que muchos, llamaba 'civilización' para 'aprovechar' todo aquello que pudiera serle útil a las nuevas repúblicas. ${ }^{1}$ Pero como probablemente tal provecho

\footnotetext{
1 En Trujillo (2020) me refiero a tres dimensiones e índoles de las concordancias en la obra de Andrés Bello, las cuales son: con las grandes potencias, con las repúblicas vecinas y con España (dimensiones); y las relaciones de orden político, comercial y lingüístico (índoles). Casi en todos los casos, Bello promovía las concordancias de cada una de estas índoles en cada una de las dimensiones, excepto en las lingüísticas, en cuyo caso advierte sobre la lógica interna de la lengua y contra el empleo indiscriminado de neologismos.
} 
sea algo más que eso, propongo ahora, con los métodos de la disciplina literaria, estudiar, desde el interior del corpus bellista, el tipo especial de provecho que Bello extrajo del acervo cultural de su tiempo y cómo fue que esa misma actividad le permitió vislumbrar una suerte de estrategia o filosofía general de eso que en aquel siglo era llamado los 'adelantamientos'.

Pero hay más. La voluminosa obra completa de Andrés Bello bien puede ser conceptualizada a efecto de hacerla trascender sus consecuencias concretas e inmediatas, de tal manera que sea concebible para ella una propuesta que pueda ser llamada actual. Este ejercicio de interpretación, que lo es también de sistematización, puede lograr — según propongo aquí- la aprehensión de un concepto cuya aparición es sin duda muy anterior a Andrés Bello, al menos en el habla castellana, pero que Bello más que resignificado, habría enriquecido. Me refiero al concepto de 'aprovechamiento', cuyas implicancias, como veremos, se extienden a variados campos.

Preliminarmente, podemos definir el concepto de 'aprovechamiento' de Bello como la acción reflexionada y medianamente concertada mediante la cual la región americana se hace consciente de su relativa independencia e identifica en el acontecer occidental aquellas cuestiones que no pueden sino ser imitadas de la experiencia comparada. De esta manera, cree Bello, América no desperdicia trabajo, se apropia de la experiencia ajena y —muy importante- descubre su riqueza específica. Existe en Bello una segunda cara del aprovechamiento: en esta segunda cara, un segundo nivel argumentativo, Bello intenta precisar el método a través del cual conocer la especificidad americana. Obviamente, para conocerla se tendrá que hacer calzar muchos puntos con la realidad universal como también con la local, al extremo de dominar detalles mínimos.

A continuación reviso el uso histórico del concepto de aprovechamiento. Sigo con una exploración del 'aprovechamiento' en el corpus de Bello, para lo cual me detengo principalmente en su aplicación en geopolítica americana como la poético-económica, entre otras. Continúo problematizando y elaborando el concepto de aprovechamiento. Finalmente, concluyo. 


\section{El aprovechamiento en el uso histórico}

El uso regular y constante ${ }^{2}$ de la voz 'aprovechamiento' está presente en español desde finales del siglo XV hasta nuestros días, tal como lo consignan diccionarios publicados en esos seis siglos; son estos catálogos los que registran la convergencia como también la variación de los léxicos. ${ }^{3}$

En los siglos XV a XVII, las primeras apariciones letradas y comparadas de la voz 'aprovechamiento' las hallamos en Nebrija, Percival y de Mez de Braidenbach. Nebrija (1495?, 19) lo define como "lo mesmo q aprovecuminto" y 'aprovechar' como "lo mesmo es que aprovecer". Por su parte, Percival $(1591,20)$ lo traduce al inglés como 'profiting' y al latín como 'profectus'; por último, Mez de Braidenbach $(1670,20)$, al alemán como Er[?]ziehung. 'Aprovechamiento', sin embargo, no aparece en importantes recopilaciones de la primera mitad del siglo XVII, tales como la de Sebastián de Covarrubias (1611) y la de John Minsheu (1617).

De 1726, el primer tomo del Diccionario de autoridades ofrece dos acepciones fundamentales: "Emolumento, utilidád, y provecho" y "El fruto y adelantamiento que se consigue en dedicarse à lo que es bueno y util: como la virtúd, los estúdios, \&c.". ${ }^{4}$ Desde entonces, es decir, la primera mitad del siglo XVIII, al menos en diccionarios bilingües aparece clara la acepción económica o utilitaria del 'aprovechamiento'. Ya en 1705, como 'Profit, utilité' lo traduce el diccionario español-francés de Francisco Sobrino $(1705,31)$; y como 'Profit, Gain, Advantage', el español-inglés de

\footnotetext{
${ }^{2}$ Como puede leerse a través de toda su Gramática de la lengua castellana (Bello 19811987h), la regularidad y lo constante de los usos en la lengua son para Bello factores determinantes para entender su legalidad interna.

${ }^{3}$ Véase la edición facsimilar preparada por la RAE del Nuevo tesoro lexicográfico de la lengua española (NTLLE). Disponible en https://www.rae.es/obras-academicas/diccionarios/nuevotesoro-lexicografico-0.

${ }^{4}$ Las dos acepciones completas dicen: la primera: "s. m. Emolumento, utilidád, y provecho. Y tambien se entiende por esta voz los emolumentos y percances que dán los empléos, además del salário que tienen assignádo. Lat. Emolumentum. Utilitas. Commodum. AMBR. MOR. Descripc. de Es Juntémos con los árboles fructíferos de España los demás que hai en ella de grandes aprovechamientos. MARQ. Gobern. Christ. lib. 1. ca 21. Entendió que le moviéra mas aquella lisónja que otros aprovechamientos. MEND. Guerr. de Gran. lib. 2. num. 26. Reformar los excessos de Capitánes y soldádos en alojamientos, contribuciones, aprovechamientos de pagas, \&c.". La segunda acepción es la siguiente: "El fruto y adelantamiento que se consigue en dedicarse à lo que es bueno y util: como la virtúd, los estúdios, \&c. Lat. Profectus. C. LUCAN. Prolog. E para salvamiento de sus ánimas, è aprovechamiento de sus cuerpos. CERV. Quix. tom. 1. ca 49. Que redunde en aprovechamiento de su conciéncia, y en aumento de su honra" (Real Academia Española 1726, 359).
} 
John Stevens (1706, 39). Décadas más tarde, estas acepciones aparecen profundizadas en el diccionario cuatrilingüe de Esteban de Terreros y Pando (1786, 133), que lo define y traduce así: "utilidad, emolumento, y provecho que se saca de alguna cosa. Fr. Profit. Lat. Lucrum, commodum, utillitas. ¿?. It. Prosfisto, utilitá, guadagno" (133); mientras que en la segunda acepción incluso dice: "la renta que se saca, ó cobra por el dinero puesto á logro, ó censo. Fr, Interets. Lat. Usura, emolumentum. It. Interesse". Por primera vez, el 'aprovechamiento' es vinculado a la usura (antes lo había estado al lucro). El de Terreros y Pando también agrega una tercera acepción: "el adelantamiento ó provecho que se hace aplicándose a alguna ciencia, arte \&c. Fr. Progrés, Lat. Prosectus, It. Profisto" (1786, 133). Años más tarde, el de Núñez de Taboada lo define simplemente como: "Provecho o utilidad" $(1825,119)$.

Además de la definición de la RAE de esos años, se agregará: “El derecho de pasto y leña concedido bajo ciertas restricciones á los vecinos de los pueblos en los montes que pertenecen al común", en el de Vicente Salvá de 1846 (90).

Como "Provecho, ó utilidad, Profectus, utilitas, fructus, emoluments, perceptio", define y ejemplifica usos la Real Academia Española. No varía sustancialmente en las ediciones de 1780, 1783, 1791, 1803, 1817, 1822, 1832, 1837, 1843 y 1852 (a partir de 1832 se reducen los equivalentes en latín). Recién en 1869, la RAE cambia la definición por “la acción y efecto de aprovechar y aprovecharse" y elimina la equivalencia latina (RAE 1869, 63), que se mantuvo idéntica en 1884, 1899, 1914 y 1925, año en que agrega a la primera acepción, una segunda: "2. V. Bienes de aprovechamiento común. || forestal. Esquilmo o producto de montes y dehesas" (RAE 1925, 100). En fin, la segunda acepción desaparece en 1927 (RAE $1927,157)$. La definición permanece más o menos idéntica al menos hasta la edición de 1992. ${ }^{5}$

\footnotetext{
${ }^{5}$ No está demás comentar algunos detalles. En la misma edición de 1869, 'aprovechar' se define y usa así: "Servir de provecho, utilidad ó adelantamiento. || a. Emplear utilmente alguna cosa; como: APROVECHAR la tela, el tiempo, etc. \| ant. Hacer provechosa ó útil alguna cosa, mejorarla. || ó APROVECHARSE. Hablando de la virtud, estudios, artes, etc., adelantar en ellas. r. Utilizarse de alguna cosa" $(1869,63)$. En 1933, el Diccionario de la Academia Española agrega usos históricos en la literatura para la voz 'aprovechamiento': "«Tantas maneras de aprovechamiento ha en ella, que, si Dios quiere que se faga así como él me dijo, que será mucha mi pro.» D. Juan Manuel, Obr., ed. Riv., t. 51, 376, col. 2. || «Pongo a la letra sin añadir ni quitar cosa alguna, más ni menos de lo que él tenía escripto en un libro que aprovechamiento de aquellas gentes en nuestra religión cristiana por menudo había cole-
} 
Otra importante: "Provecho, utilidad, ventaja, beneficio, etc. que se saca de algo, Adelantamiento, progreso, desarrollo moral, lucimiento, brillantez, etc., especialmente refiriéndose á los adelantos hechos en las ciencias, en las artes, en cualquiera de los ramos del saber", define el Gran Diccionario Clásico de R. J. Domínguez, de 1853 (146).

En la vejez y tras la muerte de Bello, la evolución de la voz continúa en algunos diccionarios importantes. "Provecho, utilidad, beneficio que se saca de alguna cosa, como renta, intereses del dinero.-met. adelantamiento, progreso, aplicación", según la define el de Gaspar y Roig (1853, 190), y como "adelantamiento, profeso, desarrollo moral, lucimiento, brillantez, etc., especialmente refiriéndose á los adelantos hechos en las ciencias, en las artes, en cualquiera de los ramos del saber", el Diccionario enciclopédico de la lengua castellana, de Elías Zerolo, de 1895 (222) en su segunda acepción.

En conclusión, los campos de significación de la voz 'aprovechamiento' se desarrollan especial y repetidamente durante el siglo XVIII. EI concepto describirá las mejoras del progreso, la rentabilidad, la utilidad. Sin una carga filosófica en especial, las aplicaciones de sus acepciones secundarias serán de naturaleza agropecuaria y forestal, y posteriormente, educacional y tecnológica. Con todo, lo que puede vislumbrarse es que la acepción de 'aprovechamiento' que repetitivamente empleará Bello es la de la utilidad, la ventaja, la renta y el progreso. Como veremos, él le dará un contenido al concepto en el que puede enmarcarse tanto su labor y producción en general como el ideario mismo de aquellas.

\section{El aprovechamiento en el corpus de Bello}

En segundo término, nos concentraremos en revisar algunas apariciones de la idea de 'aprovechamiento' en el corpus de Bello. Como veremos, estas apariciones podemos considerarlas hitos para formular una sistemática del 'aprovechamiento'.

gido.» B. Casas, Apol. Hist. de Indias, t. 13, 62, col. 2. || «Me daré tal priesa a lo que tengo de hacer, que vos veáis aún más de lo que os he dicho, con aprovechamiento de mi persona.» Cervantes, Nov., ed. Riv, t. 1, 162. || «Haréis, como virtuoso, elección de los libros de quien podáis sacar mayor aprovechamiento.» Suárez de Figueroa, El Pasajero, ed. 1913, 330. || «Lo dispuesto en el artículo anterior es aplicable a las servidumbres establecidas para el aprovechamiento de leñas.» Código Civil, 1888, art. 604" (RAE 1933, 698). 
Por ejemplo, en la correspondencia de Bello, el 'aprovechamiento' se manifiesta ya en encargos a Bello que se le hacen desde Caracas, muchos de ellos de naturaleza pedestre (Sambrano Urdaneta 1981, xlii).

Una de las primeras apariciones del concepto, digna de atención, la encontramos precisamente en una carta personal de Bello, pero no de su propia pluma. Se trata de la carta que Juan Germán Roscio, fechada en Caracas, el 10 de septiembre de 1810, en la cual Roscio comenta los últimos acontecimientos internacionales, específicamente la situación de los españoles enfrentados a la invasión francesa:

Ya V. sabe que desde los primeros pasos de la santa revolución de España nos predicaron los papeles públicos que era necesario que siguiésemos la suerte de la Península para que no se interrumpiese la esclavitud y su aprovechamiento. En tal caso serían más esclavos los españoles americanos, porque tenían dos señores a quien servir: señores franceses, y señores españoles. Los europeos que viven entre nosotros en la mayor parte aspiran al mismo fin para seguir su comunicación con los países donde tuvieron su nacimiento con sus amigos y parientes, con las casas de comercio de Cádiz, y demás puertos y lugares del mercado, ocupados ya por Napoleón. (Roscio, en Bello 1981-1987d, 15-16)

Vemos en esta carta un típico caso en que la voz 'aprovechamiento' aparece denotando la astucia estratégica que debieran lucir los americanos para no desperdiciar oportunidades en la coyuntura de la invasión de Napoleón a España, la retención de Fernando VII y la actuación de las Cortes en Cádiz.

Mucho más tarde, con ocasión de la polémica de estilo-historiográfica entre Bello, Lastarria y (su testaferro) Jacinto Chacón, mejor conocida como aquella acerca de los modos de 'estudiar' y 'escribir' la historia (Jaksić 2013), Bello postula la siguiente tesis histórica seguida de una propuesta de acción político-académica:

Es una especie de fatalidad la que subyuga las naciones que empiezan a las que las han precedido. Grecia avasalló a Roma; Grecia y Roma a los pueblos modernos de Europa, cuando en ésta se restauraron las letras; y nosotros somos ahora arrastrados más allá de lo justo por la influencia de la Europa, a quien, al mismo tiempo que nos aprovechamos de sus luces, debiéramos imitar en la independencia del pensamiento. (Bello 19811987e, 250)

Tendré ocasión de comentar in extenso este fundamental párrafo, pero digamos por ahora que en el concepto que Bello formula aquí está 
contenida toda la densidad geopolítica que hace de la propuesta de Bello una idea tan propia. Romper la fatalidad histórica significaría resistirse al ser arrastrado 'más allá de lo justo' por el principal foco de atracción cultural que es Europa, pero no mediante una independencia autárquica y antojadiza, incapaz, a la larga, de defender sus propios logros, sino que sirviéndose de Europa —esto es, la 'civilización' - en todo lo que signifique no verse arrastrado por su apetencia de dominación.

En lo que concierne al 'aprovechamiento' en política, en 1836 Bello publica el que podría ser calificado de un verdadero y completo programa del 'aprovechamiento' americano. En un artículo publicado en El Araucano, Bello (1981-1987f) señala que la idiosincrasia chilena y americana no es óbice para librarse de las 'instituciones libres.' Luego, hace un diagnóstico de la crispación americana para argumentar que ella no es insuperable y que seguramente la incorporación de las instituciones libres significará tener que adaptarlas mas no afectarlas en su esencia. Hasta aquí pareciera que la síntesis que plantea Bello no es muy distinta de otras de similares características que siguen la dialéctica: Europa (llustración) / América (Dominación) = República americana. Bello agrega un argumento que reconfigura toda la dialéctica anterior: precisa que Estados Unidos - un caso americano- es, lo que podríamos llamar aquí, un ejemplar mal ejemplo, y precisa que ha podido combinar la repugnante esclavitud de millones de personas con las instituciones de la libertad. Es decir, el estómago aprovechador de Bello es incluso capaz de digerir la incongruencia del esclavismo estadounidense, no para efectos de imitarla (pues Hispanoamérica ha abolido la esclavitud) sino que, más bien, para efectos de saber sobreponerse a las señales contrariantes. No contento con eso, Bello, en una actitud mitad oracular, presagia que América llegará a constituirse en el portento del mundo entero, es decir que, lejos de quedar circunscrita a reflejo del viejo mundo, ella desempeñará un papel reconfigurador de lo hasta entonces conocido. Su argumento termina con una apología del caso chileno. Ve en Chile un país que ha hecho de la ley sus armas y que en ocasiones por naturaleza tempestuosas como los momentos eleccionarios, Chile demuestra un irrestricto compromiso con la paz, cuyos resultados ejemplares podrán ser aprovechados por el resto del continente. Este laboratorio providencial chileno - que anuncia, con todo, otras tempestades del siglo XIX-es una demostración, para Bello, práctica y no meramente teórica, 
de los beneficios de lo que hemos llamado aquí el programa político del aprovechamiento. $^{6}$

En lo que podríamos denominar un segundo momento, de orden multilateral, Bello hace ver que existe un tráfico internacional, una suerte de dependencia universal de la que participan incluso las naciones más 'aventajadas' y 'prósperas'. Bello así argumenta que el sentimiento de 'dignidad' implícito en el ánimo de independencia radical no es buen Para más detalles, cito: "Reconociendo la necesidad de adaptar las formas gubernativas
a las localidades, costumbres y caracteres nacionales, no por eso debemos creer que nos
es negado vivir bajo el amparo de instituciones libres, y naturalizar en nuestro suelo las
saludables garantías que aseguran la libertad, patrimonio de toda sociedad humana, que
merezca el hombre de tal. En América, el estado de desasosiego y vacilación que ha podido
asustar a los amigos de la humanidad, es puramente transitorio. Cualesquiera que fuesen
las circunstancias que acompañasen a la adquisición de nuestra independencia, debió
pensarse que el tiempo y la experiencia irían rectificando los errores, la observación descu-
briendo las inclinaciones, las costumbres y el carácter de nuestros pueblos, y la prudencia
combinando todos estos elementos, para formar con ellos la base de nuestra organización.
Obstáculos que parecen invencibles desaparecerán gradualmente: principios tutelares,
sin alterarse en la sustancia, recibirán en sus formas externas las modificaciones necesa-
rias, para acomodarse a la posición peculiar de cada pueblo; y tendremos constituciones
estables, que afiancen la libertad e independencia, al mismo tiempo que el orden y la tran-
quilidad, y a cuya sombra podamos consolidarnos y engrandecernos. Por mucho que se
exagere la oposición de nuestro estado social con algunas de las instituciones de los pue-
blos libres, ¿se podrá nunca imaginar un fenómeno más raro que el que ofrecen los mismos
Estados Unidos en la vasta libertad que constituye el fundamento de su sistema político, y
en la esclavitud en que gimen casi dos millones de negros bajo el azote de crueles propie-
tarios? Y sin embargo, aquella nación está constituida y próspera.

Entre tanto, nada más natural que sufrir las calamidades que afectan a los pueblos en los primeros ensayos de la carrera política; mas ellas tendrán término; y la América desempeñará en el mundo el papel distinguido a que la llaman la grande extensión de su territorio, las preciosas y variadas producciones de su suelo, y tantos elementos de prosperidad que encierra.

Durante este período de transición, es verdaderamente satisfactorio, para los habitantes de Chile, ver que se goza en esta parte de la América una época de paz, que ya se deba a nuestras instituciones, ya al espíritu de orden, que distingue el carácter nacional, ya a las lecciones de pasadas desgracias, ha alejado de nosotros las escenas de horror que han afligido a otras secciones del continente americano. En Chile, están armados los pueblos por la ley; pero hasta ahora esas armas no han servido, sino para sostener el orden, y el goce de los más preciosos bienes sociales; y esta consoladora observación aumenta en importancia al fijar nuestra vista en las presentes circunstancias, en que se ocupa la nación en las elecciones, para la primera magistratura. Las tempestuosas agitaciones, que suelen acompañar estas crisis políticas, no turban nuestra quietud; los odios duermen; las pasiones no se disputan el terreno; la circunspección y la prudencia acompañan al ejercicio de la parte más interesante de los derechos políticos. Sin embargo, estas mismas consideraciones causan el desaliento y tal vez la desesperación de otros.

Querrían que este acto fuese solemnizado con tumultos populares, que le presidiese todo género de desenfreno, que se pusiesen en peligro el orden y las más caras garantías. ¡Oh! ¡nunca lleguen a verificarse en Chile estos deseos!" (Bello 1981-1987f, 224-225). 
consejero a la hora de calcular fríamente cuál será la negociación a la que habrá que concurrir si se quiere participar de los beneficios del sistema internacional. Este es el punto en que el 'aprovechamiento' mutuo no significa desaprovechamiento ni propio ni ajeno.

En un extensísimo artículo que se conoce como Tratado con la Gran Bretaña, publicado por partes en El Araucano (números 751, 753 y 755, de 10 y 24 de enero y 7 de febrero de 1845), Bello lo explica en estos términos:

\footnotetext{
Las naciones trafican con sus derechos mercantiles, como con sus demás propiedades; los cambian por otros derechos; y lo que debe verse es si ganan o pierden en el cambio. Los tratados, se dice, se versan puramente sobre cosas. Así es en último resultado; pero para llegar a una de ellas, es necesario constituir un derecho; lo que no sabemos que pueda jamás efectuarse, sin sujetarnos a una obligación, sin despojarnos de alguna de las facultades inherentes a la independencia, y la libertad del estado de naturaleza. ¿Queremos ser más independientes, más celosos de la dignidad nacional, que la Francia o la Inglaterra, y más libres que los Estados Unidos de América? A los que así pensasen, les recordaríamos que lo sublime suele estar a veces muy cerca de lo ridículo. (Bello 1981-1987g, 611)
}

El 'aprovechamiento' de las letras, en especial la poesía y la economía, es otro caso. Durán Luzio (1999) sostiene que lo que Bello intenta es conseguir una 'ecúmene' de la que Hispanoamérica forme parte, eso que ya he llamado la reconciliación entre imperio y civilización (Trujillo 2019). Sostiene que, según Bello, el déficit de los pueblos hispanoamericanos está en el silencio, que estos no tienen una trama conocida, y por eso la poesía y la historia deben hablar de estas cosas (la poesía y la historia suelen hermanarse en esquemas imperiales). Bello, obviamente, ocupa su papel y dice: "Dios de la memoria, himnos te pide/ el imperio también de Motezuma”, en la 'Alocución a la poesía' (Bello 1981-1987b, vv. 284-285).

A través de la conciencia de 'logro' histórica — tal vez propia de un protopositivismo en Bello-, política y poesía entran en una alianza orgánica. Así ocurre tempranamente con la oda "A la vacuna", que data del tiempo de la expedición de Balmis por el Imperio español que se detuvo en Caracas a difundir este beneficio. La actitud de Bello ante la vacuna es doble pues, por un lado, se la agradece a la 'Gran Providencia', pero por el otro al rey Carlos IV. Obviamente puede decirse que los méritos de Carlos IV se subsumen en la Providencia, pero Bello insiste en connotar más los méritos humanos que las gracias divinas, en tanto que - $-\mathrm{y}$ esto 
es fundamental - insta a la dependencia dentro de un contexto en que las autonomías políticas están a la orden del día. Escribe en 'A la vacuna':

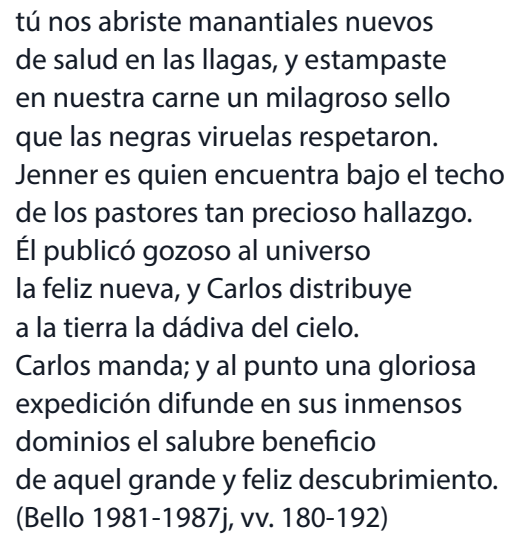

La dependencia 'marca' 'milagrosamente' 'los cuerpos'. Esta señal de Caín, que denota un aura providencial, no es ni fruto de la naturaleza, la autoctonía ni, por supuesto, la independencia - que, repito, por entonces circula como una moda solapada - con un monarca que es, por así decirlo, el delivery del cielo. Pero también Bello menciona a quien divulga 'al universo' (es decir, a la mutua dependencia de la mecánica newtoniana) 'la feliz nueva' (otra forma de decir buena nueva), el poeta y médico rural Edward Jenner (1749-1823), el inventor de la inmunología artificial, quien es considerado el descubridor de la vacuna. El provecho que saca Jenner de su vecindad campesina (observando su inmunología natural) es aprovechado por el rey Carlos IV. Los criollos no podrán sino aprovecharse de la 'distribución' que hace su rey, por mucho que ya no les guste. La creación poética saca provecho de este episodio de dimensiones universales. La inspiración cientificista de Bello no será posible más tarde con el auge del anticientifismo romántico. $\mathrm{O}$ bien, tendrá que recurrir a otras estrategias.

El provecho en la América tropical está amenazado por su suerte. Esta suerte que es su abundancia - 'que tiene por lindero el horizonte', como dice en la 'Silva a la agricultura en la zona tórrida' (Bello 19811987a, v. 15) - , es saludada por Bello en los primeros versos en que el sol mismo aparece como capturado por la zona a la que su luz fecunda:

¡Salve, fecunda zona, que al sol enamorado circunscribes 
el vago curso, y cuanto ser se anima

en cada vario clima,

acariciada de su luz, concibes! (Bello 1981-1987a, vv. 1-5)

En tanto, la suerte de la zona tórrida "solazará el fastidio al ocio inerte" (Bello 1981-1987a, v. 32), porque en ella el trabajo, es decir, la agricultura, es una exageración. Bello pasa revista a los frutales endógenos e introducidos que se dan exuberantes en el trópico. Se detiene en el banano, y en una nota explicativa apunta que es el fruto principal que comen los esclavos porque "el bananal no sólo da, a proporción del terreno que ocupa, más cantidad de alimento que ninguna otra siembra o plantío, sino que de todos los vegetales alimenticios, éste es el que pide menos trabajo y menos cuidado" (Bello 1981-1987a, 66). Dice en la silva que citamos:

\author{
el banano, primero \\ de cuantos concedió bellos presentes \\ Providencia a las gentes \\ del ecuador feliz con mano larga. \\ No ya de humanas artes obligado \\ el premio rinde opimo; \\ no es a la podadera, no al arado \\ deudor de su racimo; \\ escasa industria bástale, cual puede \\ hurtar a sus fatigas mano esclava; \\ crece veloz, y cuando exhausto acaba, \\ adulta prole en torno le sucede. \\ (Bello 1981-1987a, vv. 52-63)
}

Así también en la palma, a la cual se puede sacar un inmenso provecho. Dice la nota de Bello: "Ninguna familia de vegetales puede competir con las palmas en la variedad de productos útiles al hombre: pan, leche, vino, aceite, fruta, ortaliza, cera, leña, cuerdas, vestido, etc." (Bello 19811987a, 66).

Entre los versos 64 y 105, Bello las emprende contra todos los vicios sociales que ampara la dadivosa 'zona fértil'. Conduce al lector a través de los pasillos y alcobas de una elite rancia que no tiene conciencia de lo que posee, es decir, que no sabe aprovechar el paraíso. Y entonces se pregunta retórico:

¿Y será que se formen de ese modo

los ánimos heroicos denodados

que fundan y sustentan los estados? 


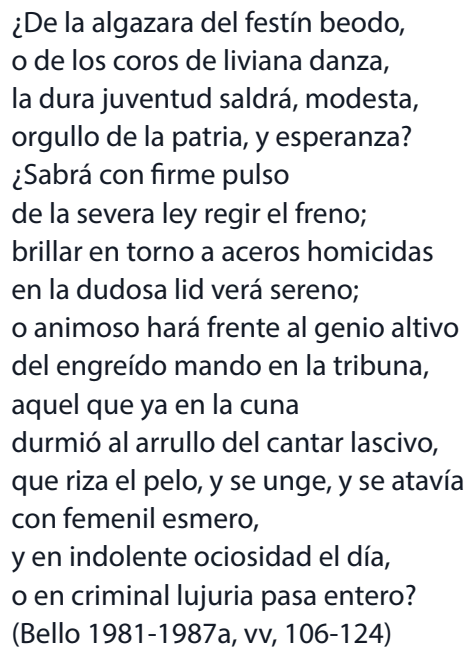

La cuestión del 'aprovechamiento' se extiende, como ya podrá barruntarse, a los límites de la cita, y con esto, del plagio, el hurto, la apropiación indebida. Sin ir más lejos, las acepciones de muchos diccionarios de los siglos XVIII y XIX asimilan el 'aprovechamiento' a 'renta,' 'lucro', pero también a 'usura', voces que en ciertas tradiciones cargan un detrimento. La liberalidad que exhibe Bello ante estos supuestos malos hábitos sugiere una posición ambigua: Bello no parece partidario de la idea romántica según la cual la creación y, todavía más, el pensamiento reflexivo, pertenezcan a un único individuo. Pero tampoco expresa de inmediato una opinión de esta índole, sino que se la reserva para una especie de meditación de más largo aliento. Así, a propósito de las acusaciones que pesaban sobre José María Pando, respecto del supuesto plagio en que habría incurrido este escritor, de algunas secciones del trabajo iusinternacionalista de Bello, quien, a decir verdad, debía buena parte de aquel al de Johann Gottlieb Heinecke, más conocido como Heinecio (16811741) y a Emer de Vattel (1714-1767), entre otros. Escribió Andrés Bello a José Gregorio Paz Soldán en 1864:

Tampoco dejaré pasar esta oportunidad sin manifestar a usted los motivos de mi silencio en orden al abuso que el señor don José María Pando se permitió hacer de la primera edición de mi Derecho Internacional. Este caballero me trató con singular distinción durante su residencia en Santiago, y yo cultivé con mucho gusto una amistad que realmente me interesaba por la amenidad de su conversación, y los conocimientos literarios y fino gusto con que la adornaba. Aunque murmurado por su misantropía, fue 
siempre conmigo un literato amable, que hasta me lisonjeaba realzando el pequeño mérito de mis producciones anteriores.

Descubierto y vituperado el plagio, como lo fue, por la juventud estudiosa de Santiago a la primera aparición de su obra, guardé por mi parte un completo silencio; y puedo decir a usted con verdad que me enorgullecí por el robo, viendo en él un voto expresivo de aprobación, porque un escritor distinguido que se apropia las ideas, y hasta copia literariamente el estilo de otro, deseando hacerlo parecer como suyo, no puede expresar de un modo más claro su favorable apreciación. Pero lo más curioso es que el libro de Pando ha sido aprobado por los publicistas ingleses, y elogiado precisamente por lo que tiene de más conforme con el mío, de manera que me hallo en el caso de decir:

Hos ego versiculos feci; tulit alter honores.

Usted no sabrá que no fue éste el único plagio con que el señor Pando se dignó honrarme. En sus Apuntes Filosóficos y Políticos (no recuerdo exactamente el título), hay también una o dos páginas mías. (Bello 1981-1987c, 465-466)

Se trate o no el párrafo de una pieza de preciosa ironía, lo cierto es que la propia producción textual de Bello — si es que es verdad que puede llamarse 'autor' a quien sabe disimular la cita de otro autor- es ella misma un superabundante conjunto de citas y paráfrasis -en el sentido de Genette (1989). Por inevitable que sea, la pregunta que aquí interesa no es tanto aquella cuya respuesta busca discernir lo que es auténticamente cosecha de Bello —insistir en aquel prurito romántico_-, para así dibujar la frontera de su figura autorial, sino que describir los flujos de su exo y macrosistema de referencias. ${ }^{7}$ En Trujillo (2019) adelanté que esta manera en que Bello está en el mundo, bien puede hacerle merecedor del título de epónimo (Trujillo 2019, 63 y 687), pero esa no es más que una manera elegante de eludir un problema que allí apenas fue enunciado (Trujillo 2019, 325). ${ }^{8}$

\footnotetext{
${ }^{7}$ Los conceptos de 'macrosistema' y 'exosistema' pertenecen a Urie Bronfenbrenner y aluden a lo que él mismo entiende como 'sistema ambiente'. Lo tomo prestado aquí con el solo fin de denotar la interconexión entre Andrés Bello y los usos de su época.

${ }^{8}$ Habiendo superado la etapa que pasa del héroe al autor (Foucault 1969) y para que el autor 'Andrés Bello' funcione de la manera menos 'ingenua', es decir, 'salvaje', estimo preciso aclarar que una de las gracias de Bello, como 'autor', y del 'aprovechamiento', como estrategia americana suya - 'su obra'-, es que nos permite observar un caso en que con mayor claridad el autor no es tanto el autor y la obra no es tanto su obra. Cuando el autor lleva muerto hace rato, Foucault se pregunta iy la obra? pues observa que no se la ha tratado con el mismo rigor que al autor. En suma, el tipo de 'obra' que hace Bello aclara que todo autor es un proyecto de plagiador, mientras que su caso es más sincero. Las transcripciones de Bello son esta sinceridad, el aprovechamiento, una filosofía de esa sinceridad. El mismo Bello parece haber sido el principal enemigo del 'exceso enigmático' (como diría Foucault
} 


\section{Entendiendo qué es el aprovechamiento}

El 'aprovechamiento' hace a Bello instalarse casi siempre a mitad de camino entre dos términos, inclinándose más o menos por uno de ellos según convenga. Por ejemplo, si se trata de dirimir entre la historia filosófica -el presupuesto según el cual es inevitable no entender filosóficamente la historia - y la historia narrativa —el presupuesto según el cual inevitablemente antes que filosofía la historia requerirá datos, hechos, archivos-, Bello observará que ello se trata de una polémica francesa que atañe a la necesidad y la utilidad de lograr una historiografía para Chile. Hará ver también que no por mucho que jóvenes progresistas como Lastarria prefieran la primera a la segunda, no será posible aquella sin esta otra, vale decir, pesará siempre sobre la filosófica la escasez de material. De esta forma, para que sea posible la historia filosófica, Bello insistirá primero en la historia narrativa, de tal suerte que la primera pueda aprovechar a la segunda. Bello no descartará ninguna, más bien las hará convivir priorizando a una sobre la otra y, al revés, estableciendo a una como meta de la otra. Por ese mismo acto, Bello toma distancia de la polémica historiográfica francesa, pero admite que no queda sino asumir los términos de la misma.

La interpretación que propongo del 'aprovechamiento' bellista no carece de contexto. Planteo que debe inscribirse, para efectos de esta investigación, en lo que podríamos denominar una 'filosofía de las concordancias', entre cuyos exponentes consideramos aquí como casos paradigmáticos a Adam Smith, G.W.F. Hegel y Carl Schmitt. El primero, especialmente en su Riqueza de las naciones, puede ser considerado un caso de coordinaciones amplias (la división del trabajo sería uno de 'aprovechamiento' mutuo); el segundo, en su Fenomenología del espíritu, supone un caso de concordancia a través de la negociación dialéctica (el amo aprende que es un poco esclavo del esclavo, y el esclavo, que es un poco amo del amo); y el tercero, en El concepto de lo político, ofrece un caso de concordancia por oposiciones irreconciliables (al saberse cada parte indefectiblemente enemiga de la otra, ambas, si bien no concuerdan en la amistad, sí concuerdan en saberse enemigas). Posiblemente,

1969) de su escritura. Con todo, lo que me importa aquí no es tanto la destrucción de la obra como más bien la búsqueda en Bello de una obra que pueda ser llamada original y americana. Una búsqueda de este tipo, sin embargo, no puede eludir los planteamientos de Foucault al respecto, aunque, por de pronto, sí podrá considerarlos anacrónicos. 
el 'aprovechamiento' haya de ser una teoría más entre las filosofías de la concordancia, pensada para la región latinoamericana de primera mitad del siglo XIX, de la misma manera como los tres autores señalados elaboraron las propias para responder a las inquietudes de sus respectivos contextos.

Ahora bien, resulta muy difícil hablar de algo así como una teoría bellista del 'aprovechamiento'. Dicha teoría, en tanto sistemática, no existe en su obra. Precisamente, lo que propongo es que, en tanto concepto, es factible de construcción a la luz de una lectura que no pierda de vista las necesidades a las que responde y los objetivos inmediatos que persigue la producción textual de Andrés Bello, pero también que descubre en el conjunto lo que pareciera ser su asunto principal. Una manera de estudiarlo es seguir el desarrollo de ciertas ideas presentes en el corpus y en los Cuadernos de Londres. $^{9}$

Las referencias al 'aprovechamiento' en la obra completa de Bello se cuentan por centenares. No es en todos los casos que se lo utiliza con densidad semántica, entendiéndose por tal la abreviación de un contenido superabundante, es decir, aquellos que son una suerte de fórmulas desglosables desde el punto de vista del análisis literario.

Según lo adelanté, un pasaje clave para este hallazgo es la discusión que Bello sostiene con Lastarria sobre los modos de escribir y estudiar la historia. En el párrafo ya citado, la fatalidad es en cierto sentido intercambiable por 'necesidad', o sea, por una fuerza, una ley, e incluso una tendencia histórica que bien pudiera considerarse negativa. Sin embargo, nadie puede querer ignorar la ley, la necesidad, la fatalidad, pues debe conocerla para, cuando sea posible, dominarla o acaso ponerse a buen recaudo de ella.

De ahí que el 'aprovechamiento' en Bello, más que una virtud necesaria, sea el resultado de una fuerza, de una 'fatalidad', como él la llama, que nos obliga a precisar dos cuestiones. Primero: ¿cuándo el otro es dig-

\footnotetext{
${ }^{9}$ Los llamados Cuadernos de Londres (Bello 2017) corresponden a una serie de cuadernos de notas que Bello tomó en la Biblioteca del Museo Británico entre los años 1814 y 1823. Por su naturaleza recolectora, estos cuadernos de notas permiten identificar los materiales primigenios y trazar la genealogía progresiva de muchas de las ideas que Bello plasmaría posteriormente en varios de sus trabajos, especialmente en la Gramática de la lengua castellana (Bello 1981-1987h), el Estudio sobre el Poema del Mio Cid (Bello 1981-1987i) como muchos de sus artículos publicados en revistas y periódicos. Para los efectos de esta investigación, la importancia de Los cuadernos de Londres radica no solo en su carácter germinal, sino también en que permiten probar su propio proceso de 'aprovechamiento'.
} 
no de ser imitado? Segundo: ¿cuándo el otro se nos adelantó en la mala experiencia? De lo cual se sigue una variante epistemológica: América está después en la historia y, como está después, necesariamente le toca no poder ser del todo original, sacar o extraer partido de tanto el error como del acierto ajenos. De lo que a su vez se sigue que la originalidad es logro de pocos. Al resto corresponderá, si es que no quiere perder valioso tiempo, incorporar ese logro como si fuera un mero dato.

Luego, el 'aprovechamiento' de Bello parece sostener que de no atenerse a esa condición existencial, esto es, el hecho forzoso de la condición americana, lo que se siga no será beneficioso sino perjudicial. Y como Bello entiende que nadie querrá, en su sano juicio, lo perjudicial, entonces el 'aprovechamiento' más que justo es necesario, pero no por eso deja de ser una acción virtuosa entenderlo así y practicarlo en consecuencia. Ahora, esa fatalidad arrastrará a los americanos 'más allá de lo justo', de tal forma que quedarán siempre presos de una paradoja: la de la independencia de pensamiento, sí, pero imitada a los europeos. Además - y esta es la astucia genial de Bello-, del hecho de que los americanos tengan que forzosamente conocer lo que ha sido antes y afuera no se sigue la pasividad del ahora, el después y el adentro. Bello explica precisamente en sus artículos estilo-historiográficos que es necesario algo así.

\section{Conclusiones}

La idea del 'aprovechamiento' es sumariar lo más que se pueda un proceso de maduración cultural destinado a lograr una síntesis propia del territorio americano. La idea de este 'aprovechamiento' será obtener en la práctica un equilibrio entre los procesos propios y los factibles de ser apropiados en los ajenos. Para Andrés Bello, todo consiste en la capacidad de encontrar el equilibrio en el caso concreto, no tanto en aras de la ecuanimidad universal, como sí del interés regional. El concepto de 'aprovechamiento' supondría un adentro y un afuera, pero también una astucia. La astucia implica un incentivo, que también puede ser entendido como un atajo fructífero, toda vez que no se trata de cualquier tipo de atajo: es uno en cuya formulación ha operado el trabajo o estudio de los materiales con que se cuenta, lo que en términos lingüísticos sería algo así como el 'sustrato' con que podría, por ejemplo, contar una planifica- 
ción lingüística. Son materiales extraídos del territorio cuya extracción no es fácil porque es una extracción que necesita poder reconocer las materias en las que se es rico. Acumulados estos materiales propios, el 'aprovechamiento' puede ser óptimo en la síntesis.

Visto así, la pregunta que surge es por el carácter de 'aprovechamiento' que habría en distintos casos. Por ejemplo, en las 'imitaciones' de Bello, especialmente las de poesías de Víctor Hugo, compuestas entre los años 1842 y 1844. Probablemente, la 'imitación' sea un estado aún inmaduro del 'aprovechamiento', por no hablar de un 'aprovechamiento' de otro orden o en menor intensidad. Lo mismo puede decirse del Código Civil de la República de Chile respecto del Código de los franceses, como también de otras de sus fuentes. El listado de textos surgidos del 'aprovechamiento' puede ser muy extenso y acaso ejemplar, pero el desafío está en su taxonomía.

Finalmente, cabe recordar que el 'aprovechamiento' es una estrategia americana para estar en el mundo. La emancipación americana necesitará saber cuál será su posición en ese mundo. Mientras Lastarria y Chacón renegarán de todo lo que han sido, Bello tendrá desconfianza de una plena asimilación del magma resultante de los dos cráteres revolucionarios, el francés y el inglés, vale decir, el político y el industrial (Hobsbawn 2015). De ahí que su preferencia por la historia narrativa sea, en el fondo, una manera de no capitular, de no entregarse sin más a un método ajeno, conservando para sí la posibilidad de un método propio (aun cuando todavía no se lo haya formulado). En este sentido, Bello podría decir lo siguiente: América no es tanto mi objeto como mi método.

Por último, cabe hacerse una pregunta principal: ¿cuál es la importancia de enfocar a la luz del concepto de 'aprovechamiento' la producción textual de Bello? Hay varias respuestas a esta pregunta, pero hay una que merece una especial reflexión. El 'aprovechamiento', según como Bello lo propone, tiene que ver con cómo una mente superabarcadora se relaciona con su tiempo y su espacio. Pareciera que Andrés Bello nunca da alguna batalla por perdida. Su declarado escepticismo está basado en un optimismo vital que, a su vez, se ocupa con exhaustividad de toda fatalidad, es decir, de todas aquellas fuerzas que se oponen a la libertad y a la originalidad, pero que, antes que desdeñarlas o exagerar su poder, deben ser utilizadas, de alguna manera, para que conspiren a favor y no en contra. De ahí que la absorción del medio sea para este autor un centro de su producción misma. 


\section{Bibliografía}

Amunátegui Aldunate, M.L. 1962. Vida de don Andrés Bello. Santiago: Prensa Latinoamericana.

Amunátegui Perelló, C. 2019. Código civil de Chile. Santiago: Tirant lo Blanch.

Arendt, H. 2013. Sobre la revolución. Madrid: Alianza.

Aron, R. 1985. Paz y guerra entre las naciones. Madrid: Alianza Universidad.

Bello, A. 1981-1987a. Silva a la agricultura en la zona tórrida (65-74). En Bello, A., Obras completas, tomo I. Caracas: La Casa de Bello.

Bello, A. 1981-1987b. Alocución a la poesía (43-64). En Obras completas, tomo I. Caracas: La Casa de Bello.

Bello, A. 1981-1987c. Carta de Bello sobre el Derecho Internacional de José María de Pando (24 de diciembre de 1864) (465-466). En Bello, A., Obras completas, tomo X. Caracas: La Casa de Bello.

Bello, A. 1981-1987d. Carta de Germán Roscio, fechada en Caracas, el 10 de septiembre de 1810 (14-16). En Bello, A., Obras completas, tomo XXV. Caracas: La Casa de Bello.

Bello, A. 1981-1987e. Modo de estudiar la historia (243-252). En Bello, A., Obras completas, tomo XXIII. Caracas: La Casa de Bello.

Bello, A. 1981-1987f. Repúblicas hispano-americanas (419-425). En Bello, A., Obras completas, tomo X. Caracas: La Casa de Bello.

Bello, A. 1981-1987g. Tratado con la Gran Bretaña (589-612). En Bello, A., Obras completas, tomo X. Caracas: La Casa de Bello.

Bello, A. 1981-1987h. Gramática de la lengua castellana destinada al uso de los americanos (5-382). En Bello, A. Obras completas, tomo IV. Caracas: La Casa de Bello.

Bello, A. 1981-1987i. Estudio sobre el Poema del Mio Cid (5-316). En Bello, A., Obras completas, tomo VII. Caracas: La Casa de Bello.

Bello, A. 1981-1987j. A la vacuna (8-15). En Bello, A., Obras completas, tomo I. Caracas: La Casa de Bello.

Bello, A. 2017. Cuadernos de Londres. Santiago: Editorial Universitaria.

Bocaz, L. 2000. Andrés Bello: una biografía cultural. Bogotá: Convenio Andrés Bello.

Caldera, R. Andrés Bello. Caracas: Biblioteca Popular Nacional.

Carilla, E. 1967. El romanticismo en la América hispánica. Madrid: Gredos.

Carrera Damas, G. 1993. De la dificultad de ser criollo. Caracas: Grijalbo.

Cesaire, A. 2006. Discurso sobre el colonialismo. Madrid: Akal.

Covarrubias, S. de 1611. Tesoro de la lengua castellana o española. Madrid: Luis Sánchez.

Cussen, A. 1998. Bello y Bolívar. México DF: Fondo de Cultura Económica.

Domínguez, R.J. 1853. Diccionario Nacional o Gran Diccionario Clásico de la Lengua Española (1846-47). Madrid-París: Establecimiento de Mellado.

Durán Luzio, J. 1999. Siete ensayos sobre Andrés Bello, el escritor. Santiago: Andrés Bello.

Dussel, E. 2007. Política de la liberación. Madrid: Trotta.

Eisenstadt, S. 1966. Los sistemas políticos de los imperios. La ascensión y la caída de las sociedades burocráticas. Madrid: Revista de Occidente.

Ferguson, N. 2012. Civilización. Occidente y el resto. Barcelona: Debate.

Foucault, M. 1969. ¿Qué es un autor? Disponible en: http://23118.psi.uba.ar/academica/carrerasdegrado/musicoterapia/informacion_adicional/311_escuelas_ psicologicas/docs/Foucault_Que_autor.pdf [15 de enero 2021]. 
García Canclini, N. 2002. Culturas híbridas. Estrategias para entrar y salir de la modernidad. Buenos Aires: Paidós.

Gaspar, J. y Roig, J. 1853. Biblioteca llustrada de Gaspar y Roig. Diccionario enciclopédico de la lengua española, con todas las vozes, frases, refranes y locuciones usadas en España y las Américas Españolas [...], tomo I. Madrid: Imprenta y Librería de Gaspar y Roig, editores.

Genette, G. 1989. Palimpsestos. La literatura en segundo grado. Madrid: Taurus.

Headrick, D.R. 2011. El poder y el imperio: la tecnología y el imperialismo de 1400 a la actualidad. Barcelona: Crítica.

Hegel, G.W.F. 1966. Fenomenología del espíritu. México DF: Fondo de Cultura Económica.

Hegel, G.W.F. 2011. Filosofía de la historia universal. Madrid: Losada.

Hobsbawn, E. 2015. La era de la revolución 1789-1848. Madrid: Crítica.

Honour, H. 1982. El neoclasicismo. Madrid: Xarait.

Honour, H. 2007. El romanticismo. Madrid: Alianza.

Jaksić, I. 2001. Andrés Bello: la pasión por el orden. Santiago: Editorial Universitaria.

Jaksić, I. 2013. Imparcialidad y verdad: El surgimiento de la historiografía chilena. Estudios Públicos 132, 141-170. Disponible en: https://estudiospublicos.cl/index. php/cep/article/view/261/321 [7 de junio 2021].

Mez de Braidenbach, N. 1670. Diccionario muy copioso de la lengua española y alemana hasta agora nunca visto, sacado de diferentes autores [...]. Viena: Juan Diego Kürner.

Minsheu, J. 1617. Vocabularium Hispanicum Latinum et Anglicum copiossisimum, cum nonnullis vocum millibus locupletatum, ac cum Linguae Hispanica Etymologijs [...]. London: Joanum Browne.

Nebrija, A. de 1495. Vocabulario español-latino. Salamanca: Impresor de la Gramática Castellana.

Núñez de Taboada 1825. Diccionario de la lengua castellana, para cuya composición se han consultado los mejores vocabularios de esta lengua y el de la Real Academia Española, últimamente publicado en 1822; aumentado con más de 5000 voces o artículos que no se hallan en ninguno de ellos. 2 vols. Paris: Seguin.

Percival, R. 1591. Bibliothecae Hispanicae pars altera. Containing Dictionarie in Spanish, English and Latine. London: s/e.

Pratt, M.L. 2002. Ojos imperiales. Ciudad de México: Fondo de Cultura Económica.

Rama, A. 2004. Ciudad letrada. Santiago: Tajamar.

Real Academia Española 1770. Diccionario de la lengua castellana compuesto por la Real Academia Española, tomo 1, A-B. Madrid: Joachín Ibarra.

Real Academia Española 1726. Diccionario de la lengua castellana, en que se explica el verdadero sentido de las voces, su naturaleza y calidad, con las phrases o modos de hablar, los proverbios o refranes, y otras cosas convenientes al uso de la lengua [...]. Compuesto por la Real Academia Española, tomo 1, A-B. Diccionario de la lengua española. Madrid: Imprenta de Francisco del Hierro.

Real Academia Española 1869. Diccionario de la lengua española. Madrid: Real Academia Española.

Real Academia Española 1925. Diccionario de la lengua española. Madrid: Real Academia Española.

Real Academia Española 1927. Diccionario de la lengua española. Madrid: Real Academia Española. 
Real Academia Española 1933. Diccionario de la lengua española. Madrid: Real Academia Española.

Real Academia Española 1992. Diccionario de la lengua española. Madrid: Real Academia Española.

Rodríguez Monegal, E. 1969. El otro Andrés Bello. Caracas: Monte Ávila.

Rojo, G. 2012. De las más altas cumbres. Teoría crítica latinoamericana moderna (18762006). Santiago: LOM.

Rudé, G. 1991. Europa, desde las guerras napoleónicas a la revolución de 1848. Madrid: Cátedra.

Said, E. W. 2018. Cultura e imperialismo. Barcelona: Debate.

Salvá, V. 1846. Nuevo diccionario de la lengua castellana, que comprende la última edición íntegra, muy rectificada y mejorada del publicado por la Academia Española, y unas veinte y seis mil voces, acepciones, frases y locuciones, entre ellas muchas americanas [...]. Paris: Vicente Salvá.

Sambrano Urdaneta, O. 1981. El epistolario de Andrés Bello (XIII-CLX). En Bello, A., Obra completa, tomo XXV. Caracas: La Casa de Bello.

Schmitt, C. 1996. Sobre los tres modos de pensar la ciencia jurídica. Madrid: Tecnos.

Schmitt, C. 1999. El concepto de lo político. Madrid: Alianza.

Smith, A. 1997. La teoría de los sentimientos morales. Madrid: Alianza.

Smith, A. 2007. An Inquiry into the Nature and Causes of the Wealth of Nations. Petersfield: Harriman House.

Sobrino, F. 1705. Diccionario nuevo de las lenguas española y francesa. Bruselas: Francisco Foppens.

Stevens, J. 1706. A New Spanish and English Dictionary. Collected from the Best Spanish Authors Both Ancient and Modern [...]. To which Is Added a Copious English and Spanish Dictionary [...]. London: George Sawbridge.

Subercaseaux, B. 1988. La apropiación cultural en el pensamiento y la cultura de América Latina. Estudios Públicos 33. Disponible en: https://estudiospublicos.cl/ index.php/cep/article/view/1589/2713 [7 de junio 2021].

Terreros y Pando, E. de 1786. Diccionario castellano con las voces de ciencias y artes y sus correspondientes en las tres lenguas francesa, latina e italiana [...], tomo 1 (1767). Madrid: Viuda de lbarra.

Trujillo, J. 2019. Andrés Bello. Libertad, imperio, estilo. Santiago: Roneo.

Trujillo, J. 2020. Concordancias del mundo en Andrés Bello. Puntos de Referencia 545. Disponible en: https://www.cepchile.cl/cep/site/docs/20200902/20200902155057/ pder545_jtrujillo.pdf [6 de septiembre 2021].

Velleman, B.L. 1995. Andrés Bello y sus libros. Caracas: La Casa de Bello.

Zerolo, E. 1895. Diccionario enciclopédico de la lengua castellana. 2 vols. París: Garnier hermanos. EP 